\title{
A GENERALIZED APPROACH TO THE SOLUTION OF ONE-DIMENSIONAL STOCK-CUTTING PROBLEM FOR SMALL SHIPYARDS
}

Ahmet Cemil Dikili

Istanbul Technical University, Department of Ocean Engineering, Maslak, 34469, Istanbul, Turkey., dikili@itu.edu.tr

Baris Barlas

Istanbul Technical University, Department of Naval Architecture and Marine Engineering, Maslak, 34469, Istanbul, Turkey.

Follow this and additional works at: https://jmstt.ntou.edu.tw/journal

Part of the Engineering Commons

\section{Recommended Citation}

Dikili, Ahmet Cemil and Barlas, Baris (2011) "A GENERALIZED APPROACH TO THE SOLUTION OF ONE-DIMENSIONAL STOCK-CUTTING PROBLEM FOR SMALL SHIPYARDS," Journal of Marine Science and Technology: Vol. 19: Iss. 4, Article 5.

DOI: $10.51400 / 2709-6998.2177$

Available at: https://jmstt.ntou.edu.tw/journal/vol19/iss4/5

This Research Article is brought to you for free and open access by Journal of Marine Science and Technology. It has been accepted for inclusion in Journal of Marine Science and Technology by an authorized editor of Journal of Marine Science and Technology. 


\section{A GENERALIZED APPROACH TO THE SOLUTION OF ONE-DIMENSIONAL STOCK- CUTTING PROBLEM FOR SMALL SHIPYARDS}

Acknowledgements

The authors would like to thank Hakan Once from the Tosyali Iron and Steel Ind. Company and the workers for giving their valuable time for cooperation. 


\title{
A GENERALIZED APPROACH TO THE SOLUTION OF ONE-DIMENSIONAL STOCK-CUTTING PROBLEM FOR SMALL SHIPYARDS
}

\author{
Ahmet Cemil Dikili* and Baris Barlas**
}

Key words: cutting, stock cutting, part nesting, linear programming, heuristic approach.

\section{ABSTRACT}

A generalized approach is introduced for the optimization of one-dimensional cutting stock problem (1D-CSP), which occurs in wide variety of engineering manufacturing processes especially in ship building industry. Instead of making preliminary specifications and accordingly ignoring many alternative arrangements, the suggested optimization technique selectively considers feasible arrangements by eliminating majority of the possible but inefficient arrangements thus rendering the problem solvable for practical applications. The introduced approach, which minimizes the piece arrangement plans and trim losses in the material, achieves the ideal solution implied by the analytical methods. Another important advantage of the present method is its ability to produce integer results, which usually cannot be obtained by means of analytical methods used in linear programming. Overall, the solution of the problem has been drastically simplified even to allow hand calculations instead of long computer runs. Thus the introduced approach can be very functional for small shipyards and single boat builders. The introduced approach is evaluated by two numerical examples.

\section{INTRODUCTION}

In industrial cutting operations, the one dimensional stock material input is a very important criterion. The cutting plans must be prepared to obtain the required set of pieces from the available stock lengths. From the automotive and the construction sectors to the ship building industry, a vast range of stock materials are used such as angles, bars, rods, U-section channel beams, I-(IPN or IPE profiles) or T-section beams, etc.

Paper submitted 08/17/09; revised 03/09/10; accepted 03/29/10. Author for correspondence: AhmetCemil Dikili (e-mail: dikili@itu.edu.tr).

*Istanbul Technical University, Department of Ocean Engineering, Maslak, 34469, Istanbul, Turkey.

**Istanbul Technical University, Department of Naval Architecture and Marine Engineering, Maslak, 34469, Istanbul, Turkey.

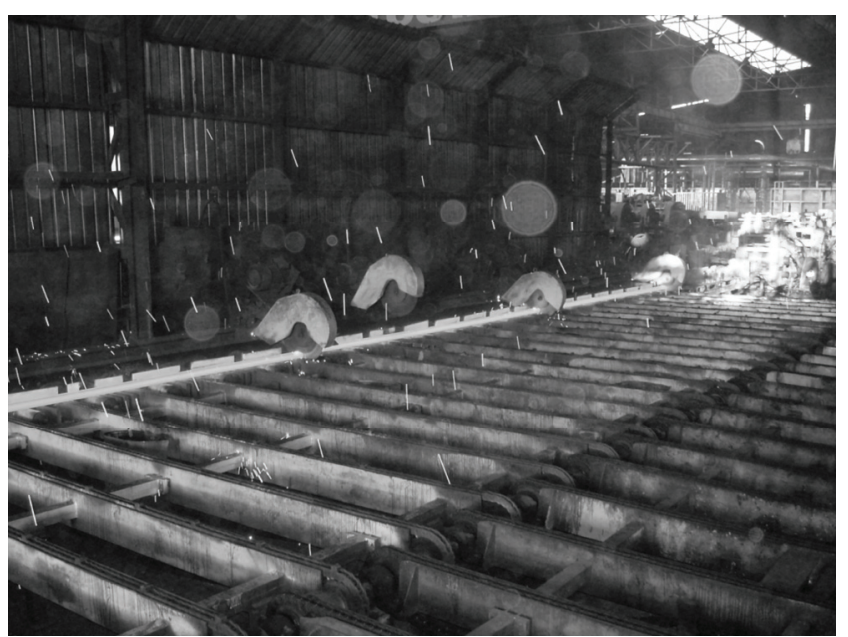

Fig. 1. The production of $U$-section channel beams in rolling mill plant.

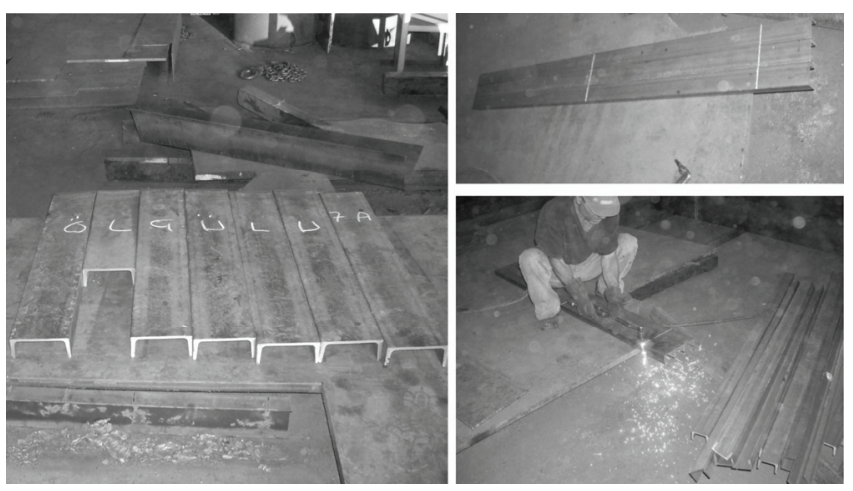

Fig. 2. The marking of the cutting patterns and cutting of $\mathbf{U}$-section channel beams.

Fig. 1 gives a snap shot photograph of the production of U-section channel beams in rolling mill plant. In Fig. 2 instances from the marking and cutting processes are shown.

The fundamental aim is to minimize the quantity of used stock material. The combination of the assortment problem and the trim loss problem is known as the cutting stock problem (CSP). In the cutting process, the whole of the stock material can rarely be used and some residual pieces are left aside as waste. Since the primary objective of the cutting process is 
to minimize the wastage, the problem is known as the trim loss problem [11].

The analytical method of optimization proposed by Gilmore and Gomory in the 1960's has proved unpractical due to too large number of possible arrangements which render the solution impossible and unusable due to results which are not integer numbers [12-14]. For instance, an average case may produce 10 million and an extreme case as high as 100 million possibilities [10]. Thus, instead of using the analytical method to obtain the ideal solution, heuristic approaches with acceptable approximations have gained popularity $[2,8,15,19,20$, 25]. Hinterding and Khan [16] have studied 1D-CSP using genetic algorithm approaches with and without contiguity. Wagner [26] have studied a 1D bundled CSP with contiguity in the lumber industry.

In recent years there have been several efforts to solve this problem by linear programming (LP) based branch-and-bound with column generation (called branch-and-price (BP)) and by general purpose Chvatal-Gomory cutting plans. Nevertheless, De Carvalho [5], Vance et al. [22], Vance [21], Vanderbeck [23], Vanderbeck [24] recently presented some attempts at combining column generation and branch-and-bound, a framework that has also been successfully applied to other integer programming problems. They were able to obtain exact solutions to quite large instances of cutting stock problems. Scheithauer et al. [18] presented an exact solution approach for the 1D-CSP which is based on a combination of the cutting plane method and the column generation technique. Belov and Scheithauer [3] proposed a cutting plane approach combining Chvatal-Gomory cutting planes where column generation is generalized for the case of multiple stock lengths in the one-dimensional cutting stock problem. Johnston and Sadinlija [17] created a new model which resolves the non-linearity between pattern variables and pattern run-lengths in the one dimensional cutting stock problem by a novel use of $0-1$ variables. Bingul and Oysu [4] suggested a new algorithm and evaluation of three one-dimensional stock cutting algorithms regarding trim loss. Belov et al. [1] investigated robust branchand-cut-and-price (BCP) algorithms, their theoretical properties and presented numerical results for BCP.

In this work, an approach which completely removes the drawbacks of the Gilmore and Gomory method, is developed to solve the 1D-CSP based on the principles first given in Dikili $[6,7]$. Even for small number of stocks Gilmore and Gomory method considers large number of meaningless possibilities with large computational time. Besides, these computations produce real numbers (fractional values) instead of integers, which are necessary in defining the number of stocks properly. Compared to the previously reported works of Dikili et al. $[8,9]$ the present work gives a more general and mathematically sound heuristic model which includes the earlier works as special cases, which is the novel aspect of this work. For instance, in Dikili et al. [8,9] only a single type of material is considered and all the material loses are gathered in minimum number of stocks. The present work on the other hand

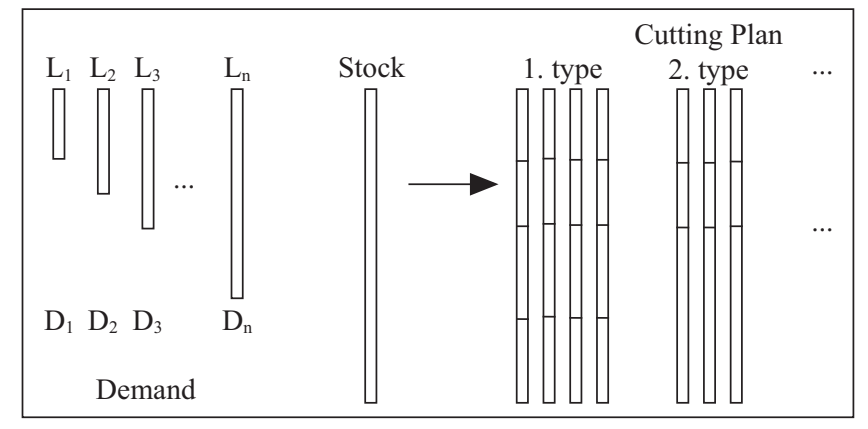

Fig. 3. 1D-CSP with one stock type.

does not contain any of these constraints and the solution is obtained without such restrictions. A successive elimination method has been proposed and the cutting plans are achieved directly without the need to establish a complicated mathematical model. The main objective of this method is to reach the optimal integer solution while minimizing the number of different patterns contained in a solution. Therefore this method can be used particularly in small shipbuilding companies, small shipyards and single boat builders without time consuming cumbersome computations. The generalized approach gives fast and reliable results within minutes for hand calculations, which are quite valuable in working environments with various different projects changing in relatively quick pace. In the next section, the 1D-CSP is introduced and the structure of the proposed algorithm is defined. In Section 3 the computational results of selected test cases are presented and the results of both the conventional and the proposed methods are compared. It is demonstrated with numerical applications that screening of all alternative patterns to reach an integer result is no longer required in this method. In Section 4 concluding remarks are presented.

\section{THE GENERALIZED APPROACH}

We now present a new method, which, when compared with the previously reported works of Dikili et al. [8, 9], gives a more general and mathematically sound heuristic approach that contains the earlier works as special cases. While in the earlier work of Dikili et al. [8,9] only a single type of material is considered and all the material loses are gathered in minimum number of stocks the present work is free of any of these constraints and the solution is obtained without such restrictions. A given set of order lengths from U-section channel beams of a fixed length (Fig. 3) is obtained by the one-dimensional cutting stock problem (1D-CSP). The objective is typically to minimize the number of stocks. The generalized approach is a combination of the conventional method and the heuristic method. The 1D-CSP is defined by the following steps:

Step 1: Assign $L_{i}$ as the length of any one of the required (demanded) material to be cut and $\mathrm{D}_{\mathrm{i}}$ the correspond- 
Table 1. Cutting patterns for elimination process.

\begin{tabular}{|c|c|c|c|c|c|c|}
\hline $\mathrm{L}_{1}$ & $\begin{array}{l}\mathrm{L}_{2} \\
\mathrm{D}_{2}\end{array}$ & $\begin{array}{l}\cdots \\
\ldots\end{array}$ & $\begin{array}{l}\mathrm{L}_{\mathrm{n}} \\
\mathrm{D}_{\mathrm{n}}\end{array}$ & $\begin{array}{l}\text { Trim Loss } \\
\text { (TL) }\end{array}$ & $\begin{array}{c}\text { Number of } \\
\text { stock } \\
\text { material }\end{array}$ & $\begin{array}{c}\text { Number of } \\
\text { parts to } \\
\text { be cut }\end{array}$ \\
\hline $\mathrm{V}_{1,1}$ & $\mathrm{~V}_{1,2}$ & ... & $\mathrm{V}_{1, \mathrm{n}}$ & $\mathrm{TL}_{1}$ & $\mathrm{SM}_{1}$ & $\mathrm{PU}_{1}$ \\
\hline $\mathrm{V}_{2,1}$ & $\mathrm{~V}_{2,2}$ & $\ldots$ & $\mathrm{V}_{2, \mathrm{n}}$ & $\mathrm{TL}_{2}$ & $\mathrm{SM}_{2}$ & $\mathrm{PU}_{2}$ \\
\hline$\ldots$ & $\ldots$ & $\ldots$ & $\ldots$ & $\ldots$ & $\ldots$ & $\ldots$ \\
\hline $\mathrm{V}_{\mathrm{K}, 1}$ & $\mathrm{~V}_{\mathrm{K}, 2}$ & $\ldots$ & $V_{K, n}$ & $\mathrm{TL}_{\mathrm{K}}$ & $\mathrm{SM}_{\mathrm{K}}$ & $\mathrm{PU}_{\mathrm{K}}$ \\
\hline
\end{tabular}

ing number of demanded pieces with length $\mathrm{L}_{\mathrm{i}}$ for $\mathrm{i}=\{1,2, \ldots, \mathrm{n}\}$ different parts to be cut from the given stock material.

Step 2: The demand list is sorted in descending order so that $\mathrm{L}_{\mathrm{i}} \geq \mathrm{L}_{\mathrm{i}+1}$ for $\forall \mathrm{i}, \mathrm{i}+1 \in \mathrm{I}$ with $\mathrm{i}=\{1,2, \ldots, \mathrm{n}\}$. The resulting parts are:

$$
\mathrm{R}=\left\{\left(\mathrm{L}_{1}, \mathrm{D}_{1}\right), \ldots,\left(\mathrm{L}_{\mathrm{i}}, \mathrm{D}_{\mathrm{i}}\right), \ldots,\left(\mathrm{L}_{\mathrm{n}}, \mathrm{D}_{\mathrm{n}}\right)\right\}
$$

Step 3: Specify the practical cutting patterns according to the demand quantity of each part, excluding the patterns which do not include the largest part in size with a specific demand quantity.

Step 3.1: For each cutting pattern determine the trim loss, the maximum number of stock material to be used considering the demand list and the total number of parts to be cut. The cutting patterns are given in Table 1.

$$
\begin{aligned}
& \text { For } \mathrm{j}=\{1, \ldots, \mathrm{K}\} \text { and } \mathrm{i}=\{1, \ldots, \mathrm{n}\}, \forall \mathrm{j} \in \mathrm{J} \\
& \mathrm{D}_{\mathrm{i}}=\text { demand quantity of the } \mathrm{i}^{\text {th }} \text { part } \\
& \mathrm{V}_{\mathrm{j}, \mathrm{I}}=\text { the quantity of } \mathrm{i}^{\text {th }} \text { part in the } \mathrm{j}^{\text {th }} \text { pattern } \\
& \mathrm{K}=\text { pattern number }
\end{aligned}
$$

Trim Loss (TL) is the difference between the stock length $\mathrm{L}$ and $\mathrm{L}_{\mathrm{i}}$. The values of Trim Loss $\left(\mathrm{TL}_{\mathrm{j}}\right)$, Stock Material $\left(\mathrm{SM}_{\mathrm{j}}\right)$, Parts Used $\left(\mathrm{PU}_{\mathrm{j}}\right)$ can be calculated using the following relationships;

$$
\begin{gathered}
T L_{j}=L-\sum_{i=1}^{n} V_{j, i} L_{i} \\
S M_{j}=\min \left(\left\lfloor D_{i} / V_{j, i}\right\rfloor\right) \\
P U_{j}=S M_{j} \sum_{i=1}^{n} V_{j, i}
\end{gathered}
$$

$V_{j, i}$ values can be calculated using the following recursive

\begin{tabular}{|c|c|c|c|c|c|c|c|c|c|c|}
\hline (100) & L: & 60 & 50 & 15 & 20 & 20 & 10 & $\begin{array}{l}\text { Trim } \\
\text { Loss } \\
(\mathrm{min})\end{array}$ & $\begin{array}{c}\text { Number } \\
\text { of stock } \\
\text { material } \\
(\max )\end{array}$ & $\begin{array}{c}\text { Number } \\
\text { of parts } \\
\text { to be cut } \\
\text { (min) }\end{array}$ \\
\hline 1 & & 1 & 0 & 1 & 0 & 0 & 1 & 0 & 6 & $18^{*}$ \\
\hline 2 & & 1 & 0 & 0 & 1 & 0 & 1 & 5 & - & - \\
\hline 3 & & 1 & 0 & 0 & 0 & 2 & 0 & 0 & 4 & - \\
\hline 4 & & 1 & 0 & 0 & 0 & 1 & 2 & 0 & 6 & 24 \\
\hline 5 & & 1 & 0 & 0 & 0 & 0 & 4 & 0 & 4 & - \\
\hline
\end{tabular}
relationship

for $\forall \mathrm{j} \in \mathrm{J}$ and $\forall \mathrm{i}, \mathrm{i}+1 \in \mathrm{I}$

$$
V_{j, i+1}=\left\lfloor\frac{\left(L-\sum_{p=1}^{i} V_{j, p} L_{p}\right)}{L_{i+1}}\right\rfloor
$$

Table 2. Definition of the parts.

\begin{tabular}{ccc}
\hline $\mathrm{i}$ & $\mathrm{L}_{\mathrm{i}}$ & $\mathrm{D}_{\mathrm{i}}$ \\
\hline 1 & 60 & 6 \\
2 & 50 & 7 \\
3 & 30 & 15 \\
4 & 25 & 20 \\
5 & 20 & 9 \\
6 & 10 & 16 \\
\hline
\end{tabular}

Table 3. The required stock material quantity and the cutting patterns.

* chosen

$$
V_{1,1}=\left\lfloor\frac{L}{L_{1}}\right\rfloor
$$

Step 3.2: Determine the best pattern according to the following order of precedence:

i- Minimum waste ratio: $\min \left(T L_{j}\right)$

ii- Maximum stock material usage: $\max \left(S M_{j}\right)$

iii- Minimum total number of parts used: $\min \left(P U_{j}\right)$

Step 3.3: Determine and store the best cutting pattern.

Step 3.4: Reorganize the demand quantities for the next elimination procedure.

Step 4: Terminate the iteration process if the cutting plan solution contains the required set of pieces else go to Step 3.

\section{COMPUTATIONAL RESULTS}

\section{First Application}

In the experiment, six different types of parts are planned to be cut from identical stock material U-section channel beams of length 100 units. The length and demand quantity of each part for this application are given in Table 2. The required stock material and the cutting patterns are given in Table 3.

Result of Table 3: Pattern number $1(1,0,1,0,0,1)$ is selected where 6 pieces of stock material are used $6 \times(1,0,1,0,0,1)$. The cutting plan is $((1)(3)(6)) \times 6$. Therefore, the cutting pattern describes the cutting of six items of part 1, part 3 and 
Table 4. The required stock material quantity and the cutting patterns.

\begin{tabular}{|c|c|c|c|c|c|c|c|c|c|c|}
\hline (100) & $\begin{array}{l}\mathrm{L}: \\
\mathrm{D}:\end{array}$ & 60 & 50 & 30 & 20 & 20 & 10 & $\begin{array}{l}\text { Trim } \\
\text { Loss } \\
\text { (min) }\end{array}$ & $\begin{array}{c}\text { Number } \\
\text { of stock } \\
\text { material } \\
(\max )\end{array}$ & $\begin{array}{c}\text { Number } \\
\text { of parts } \\
\text { to be cut } \\
\text { (min) }\end{array}$ \\
\hline 1 & & & 2 & 0 & 0 & 0 & 0 & 0 & 3 & 6 \\
\hline 2 & & & 1 & 1 & 0 & 1 & 0 & 0 & 7 & $21^{*}$ \\
\hline 3 & & & 1 & 1 & 0 & 0 & 2 & 0 & 5 & - \\
\hline 4 & & & 1 & 0 & 2 & 0 & 0 & 0 & 7 & 21 \\
\hline 5 & & & 1 & 0 & 1 & 1 & 0 & 5 & - & - \\
\hline 6 & & & 1 & 0 & 1 & 0 & 2 & 5 & - & - \\
\hline 7 & & & 1 & 0 & 0 & 2 & 1 & 0 & 4 & - \\
\hline 8 & & & 1 & 0 & 0 & 1 & 3 & 0 & 3 & - \\
\hline 9 & & & 1 & 0 & 0 & 0 & 5 & 0 & 2 & - \\
\hline
\end{tabular}

* chosen

Table 5. The required stock material quantity and the cutting patterns.

\begin{tabular}{|c|c|c|c|c|c|c|c|c|c|c|}
\hline (100) & L: & 60 & 50 & 30 & 20 & 20 & 10 & $\begin{array}{l}\text { Trim } \\
\text { Loss } \\
(\mathrm{min})\end{array}$ & $\begin{array}{c}\text { Number } \\
\text { of stock } \\
\text { material } \\
(\max )\end{array}$ & $\begin{array}{c}\text { Number } \\
\text { of parts } \\
\text { to be cut } \\
\text { (min) }\end{array}$ \\
\hline 1 & & & & 2 & 1 & 0 & 1 & 5 & 1 & 4 \\
\hline 2 & & & & 2 & 0 & 2 & 0 & 0 & 1 & 4 \\
\hline 3 & & & & 2 & 0 & 1 & 2 & 0 & 1 & 5 \\
\hline 4 & & & & 2 & 0 & 0 & 4 & 0 & 1 & 6 \\
\hline 5 & & & & 1 & 2 & 1 & 0 & 0 & 2 & $8^{*}$ \\
\hline 6 & & & & 1 & 2 & 0 & 2 & 0 & 2 & 10 \\
\hline 7 & & & & 1 & 1 & 2 & 0 & 5 & - & - \\
\hline 8 & & & & 1 & 1 & 1 & 2 & 5 & - & - \\
\hline 9 & & & & 1 & 1 & 0 & 4 & 5 & - & - \\
\hline 10 & & & & 1 & 0 & 2 & 3 & 0 & 1 & - \\
\hline 11 & & & & 1 & 0 & 1 & 5 & 0 & 2 & 14 \\
\hline 12 & & & & 1 & 0 & 0 & 7 & 0 & 1 & - \\
\hline
\end{tabular}

* chosen

part 6 from the stock length. Then, the demand quantity of each part is reorganized for the next elimination procedure. The required stock material and the cutting patterns are given in Table 4.

Result of Table 4: Pattern number $2(0,1,1,0,1,0)$ is selected where 7 pieces of stock material are used $7 \times(0,1,1,0,1,0)$. The cutting plan is $((2)(3)(5)) \times 7$. Therefore, the cutting pattern describes the cutting of seven items of part 2, part 3 and part 5 from the stock length. Then, the demand quantity of each part is reorganized for the next elimination procedure. The required stock material and the cutting patterns are given in Table 5.

Result of Table 5: Pattern number $5(0,0,1,2,1,0)$ is selected where 2 pieces of stock material are used $2 \times(0,0,1,2,1,0)$.
Table 6. The required stock material quantity and the cutting patterns.

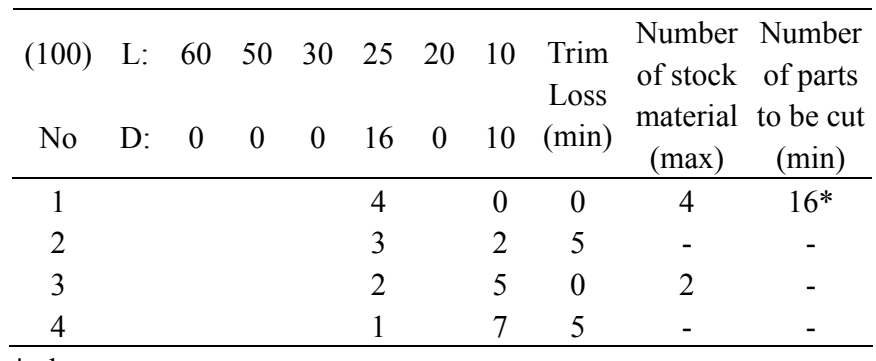

* chosen

Table 7. The required stock material quantity and the cutting patterns.

\begin{tabular}{cccccccccccc}
\hline$(100)$ & L: & 60 & 50 & 30 & 25 & 20 & 10 & $\begin{array}{c}\text { Trim } \\
\text { Loss }\end{array} \begin{array}{c}\text { Number } \\
\text { of stock } \\
\text { material } \\
\text { No parts } \\
\text { to be cut } \\
(\min )\end{array}$ \\
\hline 1 & D: & 0 & 0 & 0 & 0 & 0 & 10 & $(\min )$ & $\begin{array}{c}\text { max }) \\
(\min \end{array}$ \\
\hline
\end{tabular}

The cutting plan is ((3) (4) (4) (5)) $\times 2$. Therefore, the cutting pattern describes the cutting of two items of part 2 and part 5, and four items of part 4 from the stock length. Then, the demand quantity of each part is reorganized for the next elimination procedure. The required stock material and the cutting patterns are given in Table 6.

Result of Table 6: Pattern number $1(0,0,0,4,0,0)$ is selected where 4 pieces of stock material are used $4 \times(0,0,0,4,0,0)$. The cutting plan is ((4) (4) (4) (4)) $\times 4$. Therefore, the cutting pattern describes the cutting of sixteen items of part 4 from the stock length. Then, the demand quantity of each part is reorganized for the next elimination procedure. The required stock material and the cutting patterns are given in Table 7.

Result of Table 7: Pattern number $1(0,0,0,0,0,10)$ is selected where 1 piece of stock material are going to be used $1 \times$ $(0,0,0,0,0,10)$. The cutting plan is ((6) (6) (6) (6) (6) (6) (6) (6) $(6)(6)) \times 1$. Therefore, the cutting pattern describes the cutting of ten items of part 6 from the stock length.

Hence, the placement of all parts in the cutting plans is achieved with 5 types of cutting pattern, using 20 stock U-section channel beams. The layout plans are given in Fig. 4. The overall process takes approximately 15 minutes by using a hand calculator.

The above example is solved by using the conventional analytical method developed by Gilmore and Gomory. First of all, the mathematical model needs to be established using all possible patterns. For this example we have 44 possible patterns given in Table 8 .

The objective function and the constraints of the problem are defined as follows: 
Table 8. Possible cutting patterns.

\begin{tabular}{cccccccccccccc}
\hline$\#$ & 1 & 2 & 3 & 4 & 5 & 6 & $\#$ & 1 & 2 & 3 & 4 & 5 & 6 \\
\hline $1-$ & 1 & 0 & 1 & 0 & 0 & 1 & $23-$ & 0 & 0 & 1 & 1 & 1 & 2 \\
$2-$ & 1 & 0 & 0 & 1 & 0 & 1 & $24-$ & 0 & 0 & 1 & 1 & 0 & 4 \\
$3-$ & 1 & 0 & 0 & 0 & 2 & 0 & $25-$ & 0 & 0 & 1 & 0 & 3 & 1 \\
$4-$ & 1 & 0 & 0 & 0 & 1 & 2 & $26-$ & 0 & 0 & 1 & 0 & 2 & 3 \\
$5-$ & 1 & 0 & 0 & 0 & 0 & 4 & $27-$ & 0 & 0 & 1 & 0 & 1 & 5 \\
$6-$ & 0 & 2 & 0 & 0 & 0 & 0 & $28-$ & 0 & 0 & 1 & 0 & 0 & 7 \\
$7-$ & 0 & 1 & 1 & 0 & 1 & 0 & $29-$ & 0 & 0 & 0 & 4 & 0 & 0 \\
$8-$ & 0 & 1 & 1 & 0 & 0 & 2 & $30-$ & 0 & 0 & 0 & 3 & 1 & 0 \\
$9-$ & 0 & 1 & 0 & 2 & 0 & 0 & $31-$ & 0 & 0 & 0 & 3 & 0 & 2 \\
$10-$ & 0 & 1 & 0 & 1 & 1 & 0 & $32-$ & 0 & 0 & 0 & 2 & 2 & 1 \\
$11-$ & 0 & 1 & 0 & 1 & 0 & 2 & $33-$ & 0 & 0 & 0 & 2 & 1 & 3 \\
$12-$ & 0 & 1 & 0 & 0 & 2 & 1 & $34-$ & 0 & 0 & 0 & 2 & 0 & 5 \\
$13-$ & 0 & 1 & 0 & 0 & 1 & 3 & $35-$ & 0 & 0 & 0 & 1 & 3 & 1 \\
$14-$ & 0 & 1 & 0 & 0 & 0 & 5 & $36-$ & 0 & 0 & 0 & 1 & 2 & 3 \\
$15-$ & 0 & 0 & 3 & 0 & 0 & 1 & $37-$ & 0 & 0 & 0 & 1 & 1 & 5 \\
$16-$ & 0 & 0 & 2 & 1 & 0 & 1 & $38-$ & 0 & 0 & 0 & 1 & 0 & 7 \\
$17-$ & 0 & 0 & 2 & 0 & 2 & 0 & $39-$ & 0 & 0 & 0 & 0 & 5 & 0 \\
$18-$ & 0 & 0 & 2 & 0 & 1 & 2 & $40-$ & 0 & 0 & 0 & 0 & 4 & 2 \\
$19-$ & 0 & 0 & 2 & 0 & 0 & 4 & $41-$ & 0 & 0 & 0 & 0 & 3 & 4 \\
$20-$ & 0 & 0 & 1 & 2 & 1 & 0 & $42-$ & 0 & 0 & 0 & 0 & 2 & 6 \\
$21-$ & 0 & 0 & 1 & 2 & 0 & 2 & $43-$ & 0 & 0 & 0 & 0 & 1 & 8 \\
$22-$ & 0 & 0 & 1 & 1 & 2 & 0 & $44-$ & 0 & 0 & 0 & 0 & 0 & 10 \\
\hline & & & & & & & & & & & & &
\end{tabular}

Cutting plan $\doteqdot((1)(3)(6)) \times 6$

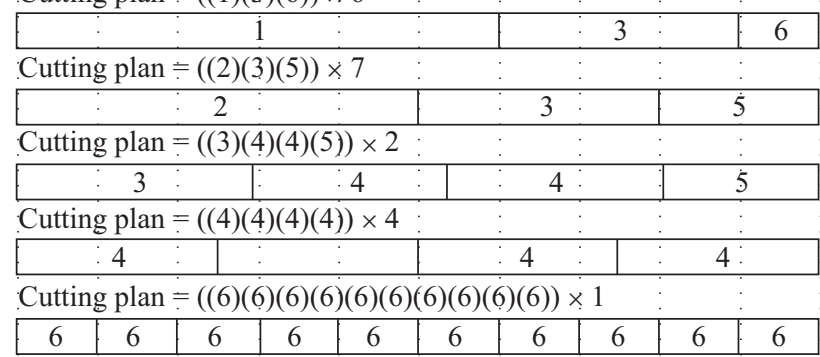

Fig. 4. The layout plans obtained by the generalized approach.

Objective function to be minimized is

$$
\min Z=\sum_{i=1}^{44} X_{i}
$$

where $X_{i}$ denotes the quantity of each pattern in the cutting plan. The constraints of the problem are defined as:

$$
\begin{gathered}
X_{i} \geq 0, i=1,2, \ldots, 44 \\
X_{1}+X_{2}+X_{3}+X_{4}+X_{5} \geq 6 \\
2 X_{6}+X_{7}+X_{8}+X_{9}+X_{10}+X_{11}+X_{12}+X_{13}+X_{14} \geq 7
\end{gathered}
$$

$$
\begin{aligned}
X_{1} & +X_{7}+X_{8}+3 X_{15}+2 X_{16}+2 X_{17}+2 X_{18}+2 X_{19}+X_{20} \\
& +X_{21}+X_{22}+X_{23}+X_{24}+X_{25}+X_{26}+X_{27}+X_{28} \geq 15 \\
X_{2} & +2 X_{9}+X_{10}+X_{11}+X_{16}+2 X_{20}+2 X_{21}+X_{22}+X_{23} \\
& +X_{24}+4 X_{29}+3 X_{30}+3 X_{31}+2 X_{32}+2 X_{33}+2 X_{34}+X_{35} \\
& +X_{36}+X_{37}+X_{38} \geq 20 \\
2 X_{3} & +X_{4}+X_{7}+X_{10}+2 X_{12}+X_{13}+2 X_{17}+X_{18}+X_{20} \\
& +2 X_{22}+X_{23}+3 X_{25}+2 X_{26}+X_{27}+X_{30}+2 X_{32} \\
& +X_{33}+3 X_{35}+2 X_{36}+X_{37}+5 X_{39}+4 X_{40}+3 X_{41} \\
& +2 X_{42}+X_{43} \geq 9 \\
X_{1} & +X_{2}+2 X_{4}+4 X_{5}+2 X_{8}+2 X_{11}+X_{12}+3 X_{13}+5 X_{14} \\
& +X_{15}+X_{16}+2 X_{18}+4 X_{19}+2 X_{21}+2 X_{23}+4 X_{24} \\
& +X_{25}+3 X_{26}+5 X_{27}+7 X_{28}+2 X_{31}+X_{32}+3 X_{33} \\
& +5 X_{34}+X_{35}+3 X_{36}+5 X_{37}+7 X_{38}+2 X_{40}+4 X_{41} \\
& +6 X_{42}+8 X_{43}+10 X_{44} \geq 16
\end{aligned}
$$

The preliminary results obtained with simplex method using the objective function (1) and the constraints (2-8) are given in Table 9. The results show that at least 20 pieces of stock material are required. However, the quantities needed for three patterns are not integers. Therefore, the resulting value can not be considered practical. When it is rounded-up to an integer, the required pieces of stock material become 21, resulting in excess production of required parts. When alternative screenings are carried out in addition to the preliminary results, a total of 25 results are obtained, which a reduced summary is given in Table 9. For the first application, only 4 out of the first case and 25 alternative solutions yield integer results. The alternative solutions which yield integer results are given in summary in Table 10 .

Amongst these alternative solutions with integer results three different solutions for 6 cutting plans and one solution for 5 cutting plans are given in Fig. 5 .

\section{Second Application}

In this application, five different types of parts whose lengths and demand quantities are given in Table 11, are required to be produced using stock materials of 100 units in length. The required stock material and the cutting patterns are given in Table 12.

Result of Table 12: Pattern number $4(1,2,0,0,0)$ is selected where 5 pieces of stock material are used $5 \times(1,2,0,0,0)$. The cutting plan is $5 \times((1)(2)(2))$. Therefore, the cutting pattern describes the cutting of five items of part 1 , and ten 
Table 9. Preliminary and some alternative solutions using simplex method for the first application.

\begin{tabular}{|c|c|c|c|c|c|}
\hline \multicolumn{2}{|c|}{ First case } & \multicolumn{2}{|c|}{$\begin{array}{c}\text { Alternative } \\
\text { solutions (4) }\end{array}$} & \multicolumn{2}{|c|}{$\begin{array}{l}\text { Alternative } \\
\text { solutions (8) }\end{array}$} \\
\hline \# & $\begin{array}{c}\# \text { of stock } \\
\text { material }\end{array}$ & \# & $\begin{array}{c}\# \text { of stock } \\
\text { material }\end{array}$ & \# & $\begin{array}{c}\text { \# of stock } \\
\text { material }\end{array}$ \\
\hline 1 & 6 & 5 & 3 & 5 & 2 \\
\hline 6 & 3.5 & 6 & 2 & 9 & 6 \\
\hline 15 & 3 & 15 & 4 & 15 & 5 \\
\hline 29 & 5 & 29 & 5 & 29 & 2 \\
\hline 39 & 1.8 & 3 & 3 & 3 & 4 \\
\hline 44 & 0.7 & 7 & 3 & 13 & 1 \\
\hline
\end{tabular}

Table 10. Two alternative solutions which yield integer results.

\begin{tabular}{|c|c|c|c|}
\hline \multicolumn{2}{|c|}{$\begin{array}{l}\text { Alternative } \\
\text { Result (4) }\end{array}$} & \multirow[b]{2}{*}{ Patterns } & \multirow[b]{2}{*}{ Cutting plan } \\
\hline \# & $\begin{array}{c}\# \text { of stock } \\
\text { material }\end{array}$ & & \\
\hline 5 & 3 & $(1,0,0,0,0,4)$ & $((1)(6)(6)(6)(6)) \times 3$ \\
\hline 6 & 2 & $(0,2,0,0,0,0)$ & $((2)(2)) \times 2$ \\
\hline 15 & 4 & $(0,0,3,0,0,1)$ & $((3)(3)(3)(6)) \times 4$ \\
\hline 29 & 5 & $(0,0,0,4,0,0)$ & $((4)(4)(4)(4)) \times 5$ \\
\hline 3 & 3 & $(1,0,0,0,2,0)$ & $((1)(5)(5)) \times 3$ \\
\hline 7 & 3 & $(0,1,1,0,1,0)$ & $((2)(3)(5)) \times 3$ \\
\hline \multicolumn{2}{|c|}{$\begin{array}{l}\text { Alternative } \\
\text { Result (8) }\end{array}$} & & \\
\hline \# & $\begin{array}{c}\# \text { of stock } \\
\text { material }\end{array}$ & Patterns & Cutting plan \\
\hline 5 & 2 & $(1,0,0,0,0,4)$ & $((1)(6)(6)(6)(6)) \times 2$ \\
\hline 9 & 6 & $(0,1,0,2,0,0)$ & $((2)(4)(4)) \times 6$ \\
\hline 15 & 5 & $(0,0,3,0,0,1)$ & $((3)(3)(3)(6)) \times 5$ \\
\hline 29 & 2 & $(0,0,0,4,0,0)$ & $((4)(4)(4)(4)) \times 2$ \\
\hline 3 & 4 & $(1,0,0,0,2,0)$ & $((1)(5)(5)) \times 4$ \\
\hline 13 & 1 & $(0,1,0,0,1,3)$ & $((2)(5)(6)(6)(6)) \times 1$ \\
\hline
\end{tabular}

Cutting plan $\div((1)(6)(6)(6)(6)) \times 3$

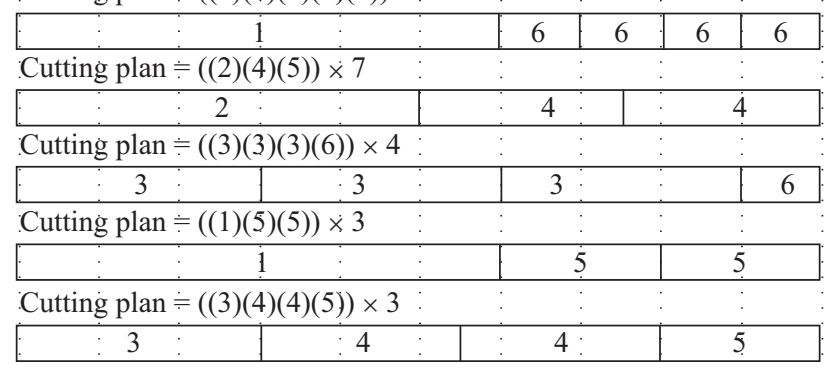

Fig. 5. The layout plans obtained by using the conventional analytical method.
Table 11. Definition of the parts.

\begin{tabular}{rrr}
\hline $\mathrm{i}$ & $\mathrm{L}_{\mathrm{i}}$ & $\mathrm{D}_{\mathrm{i}}$ \\
\hline 1 & 40 & 7 \\
2 & 30 & 10 \\
3 & 20 & 6 \\
4 & 10 & 4 \\
5 & 5 & 2 \\
\hline
\end{tabular}

Table 12. Required stock material quantity and possible cutting patterns.

\begin{tabular}{|c|c|c|c|c|c|c|c|c|c|}
\hline (100) & L: & 40 & 30 & 20 & 10 & 2 & $\begin{array}{l}\text { Trim } \\
\text { Loss } \\
(\mathrm{min})\end{array}$ & $\begin{array}{c}\text { Number } \\
\text { of stock } \\
\text { material } \\
(\max )\end{array}$ & $\begin{array}{l}\text { Number } \\
\text { of parts to } \\
\text { be cut } \\
\text { (min) }\end{array}$ \\
\hline 1 & & 2 & 0 & 1 & 0 & 0 & 0 & 3 & 15 \\
\hline 2 & & 2 & 0 & 0 & 2 & 0 & 0 & 2 & - \\
\hline 3 & & 2 & 0 & 0 & 1 & 2 & 0 & 1 & - \\
\hline 4 & & 1 & 2 & 0 & 0 & 0 & 0 & 5 & $15^{*}$ \\
\hline 5 & & 1 & 1 & 1 & 1 & 0 & 0 & 4 & - \\
\hline 6 & & 1 & 1 & 1 & 0 & 2 & 0 & 1 & - \\
\hline 7 & & 1 & 1 & 0 & 3 & 0 & 0 & 1 & 24 \\
\hline 8 & & 1 & 1 & 0 & 2 & 2 & 0 & 1 & - \\
\hline 9 & & 1 & 0 & 3 & 0 & 0 & 0 & 2 & - \\
\hline 10 & & 1 & 0 & 2 & 2 & 0 & 0 & 2 & - \\
\hline 11 & & 1 & 0 & 2 & 1 & 2 & 0 & 1 & - \\
\hline 12 & & 1 & 0 & 1 & 4 & 2 & 0 & 1 & - \\
\hline 13 & & 1 & 0 & 1 & 3 & 2 & 0 & 1 & - \\
\hline
\end{tabular}

* chosen

Table 13. Possible cutting patterns and the columns required.

\begin{tabular}{cccccccccc}
\hline$(100)$ & L: & 40 & 30 & 20 & 10 & 5 & $\begin{array}{c}\text { Trim } \\
\text { Loss } \\
(\min )\end{array}$ & $\begin{array}{c}\text { Number } \\
\text { of stock } \\
\text { material } \\
(\max )\end{array}$ & $\begin{array}{c}\text { Number } \\
\text { of parts to } \\
\text { bo cut } \\
(\mathrm{min})\end{array}$ \\
\hline 1 & D: & 2 & 0 & 6 & 4 & 2 & 1 & 3 \\
2 & 2 & & 1 & 0 & 0 & 0 & 1 & 8 \\
3 & 2 & & 0 & 2 & 0 & 0 & 1 & 5 \\
4 & 2 & 0 & 1 & 2 & 0 & 1 & $8 *$ \\
5 & 1 & 3 & 0 & 0 & 0 & 2 & 10 \\
6 & 1 & 2 & 2 & 0 & 0 & 2 & - \\
7 & 1 & 2 & 1 & 2 & 0 & 1 & - \\
8 & 1 & 1 & 4 & 0 & 0 & 1 & - \\
9 & 1 & 1 & 3 & 2 & 0 & 1 & - \\
\hline
\end{tabular}

* chosen

items of part 2 from the stock length. Then, the demand quantity of each part is reorganized for the next elimination procedure. The required stock material and the cutting patterns are given in Table 13. 
Table 14. Possible cutting patterns and the columns required.

\begin{tabular}{|c|c|c|c|c|c|c|c|c|c|}
\hline (100) & L: & 40 & 30 & 20 & 10 & 5 & & $\begin{array}{c}\text { Number of } \\
\text { stock }\end{array}$ & $\begin{array}{l}\text { Number } \\
\text { of parts }\end{array}$ \\
\hline No & D: & 0 & 0 & 0 & 4 & 2 & $\begin{array}{l}\text { Loss } \\
(\mathrm{min})\end{array}$ & $\begin{array}{c}\text { material } \\
(\max )\end{array}$ & $\begin{array}{l}\text { to be cut } \\
\text { (min) }\end{array}$ \\
\hline 1 & & & & & 4 & 2 & & remaining pa & arts \\
\hline
\end{tabular}

\begin{tabular}{|c|c|c|c|c|c|c|}
\hline & & 1 & & 2 & & 2 \\
\hline \multicolumn{7}{|c|}{ Cutting plan $=((1)(3)(3)(3)) \times 2$} \\
\hline & & & & 3 & $\dot{3}$ & 3 \\
\hline \multicolumn{5}{|c|}{ Cutting plan $\doteqdot((4)(4)(4)(4)(5)(5)): \times 1$} & $:$ & \\
\hline$: 4$ & 4 & 4 & 4 & \begin{tabular}{l|l|l|}
5 & 5 & \\
\end{tabular} & & \\
\hline
\end{tabular}

Fig. 6. The layout plans obtained by the generalized approach.

Result of Table 13: Pattern number $4(1,0,3,0,0)$ is selected where 2 pieces of stock material are used $2 \times(1,0,3,0,0)$. The cutting plan is $2 \times((1)$ (3) (3) (3)). Therefore, the cutting pattern describes the cutting of two items of part 1 , and six items of part 3 from the stock length. Then, the demand quantity of each part is reorganized for the next elimination procedure. The required stock material and the cutting patterns are given in Table 14.

Result of Table 14: Pattern number $1(0,0,0,4,2)$ is selected where 2 pieces of stock material are used $2 \times(0,0,0,4,2)$. The cutting plan is $1 \times((4)$ (4) (4) (4) (5) (5)). Therefore, the cutting pattern describes the cutting of four items of part 4 , and two items of part 5 from the stock length. As seen from Fig. 6, totally, 8 pieces of stock material are used and 3 layout patterns are obtained. The overall process takes approximately 12 minutes by using a hand calculator.

For this problem set, a total of 94 possible patterns are obtained. To obtain the optimal integer solution by using the linear programming model, 58 alternative solutions are screened. The preliminary and alternative results are given in Table 15. From these 58 plans, the last layout plan (Alternative Result (58)) uses 7.5 pieces of stock material. The layout plan is given in Fig. 7.

With the aid of a numerical example given above, the conventional analytical method and the developed method are compared, using a Pentium-4 $3.0 \mathrm{GHz}$ computer. The results obtained by both methods are summarized in Table 16. In this comparison, the production parts are planned to be cut from identical stock U-section channel beams of length 100 units. The numbers of part types are increased from 5 to 40 gradually and the part lengths vary randomly from 5 to 60 units. With increasing number of part types, the difference between the possible patterns considered in the generalized approach and
Table 15. Preliminary and alternative results.

\begin{tabular}{|c|c|c|c|}
\hline \multicolumn{4}{|c|}{ First case } \\
\hline \multicolumn{2}{|c|}{$\#$} & \multicolumn{2}{|r|}{ \# of stock material } \\
\hline \multicolumn{2}{|c|}{1} & \multicolumn{2}{|r|}{1} \\
\hline \multicolumn{2}{|c|}{5} & \multicolumn{2}{|r|}{5} \\
\hline \multicolumn{2}{|c|}{59} & \multicolumn{2}{|r|}{1} \\
\hline \multicolumn{2}{|c|}{84} & \multicolumn{2}{|r|}{0.4} \\
\hline \multicolumn{2}{|c|}{94} & \multicolumn{2}{|r|}{0.1} \\
\hline \multicolumn{4}{|c|}{ Alternative } \\
\hline \multicolumn{4}{|c|}{ Result (58) } \\
\hline \# & $\begin{array}{c}\text { \# of stock } \\
\text { material }\end{array}$ & Patterns & Cutting plan \\
\hline 62 & 0.5 & $(0,0,4,0,4)$ & $((3)(3)(3)(3)(5)(5)(5)(5)) \times 0.5$ \\
\hline 5 & 5 & $(1,2,0,0,0)$ & $\quad((1)(2)(2)) \times 5$ \\
\hline 59 & 0 & - & - \\
\hline 61 & 0 & - & - \\
\hline 13 & 2 & $(1,0,2,2,0)$ & $((1)(3)(3)(4)(4)) \times 2$ \\
\hline
\end{tabular}

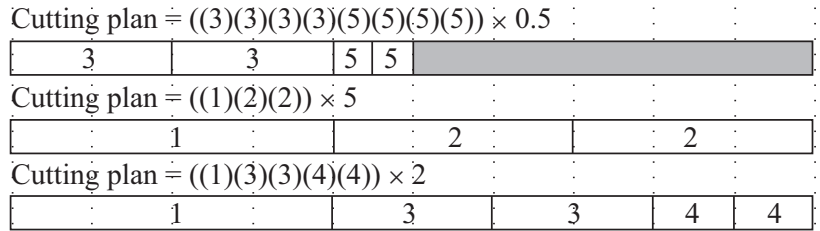

Fig. 7. The layout plans obtained by using the conventional analytical method.

the analytical method is found to increase dramatically, up to 600 times. The file sizes are also given. It should be noted that the files also contain extra information on the layouts. In the last column the ratio of the generalized method patterns to the analytical method patterns, which would approximately mean the fraction of computational time required for the present method in comparison with the analytical method is presented.

\section{CONCLUSION}

In this work, an approach which completely removes the drawbacks of the conventional analytical method by Gilmore and Gomory method, is developed to solve 1D-CSP. A successive elimination method has been proposed and the cutting plans are achieved directly without the need to establish a mathematical model. The introduced approach, which minimizes the piece arrangement plans and trim losses in the stock material, achieves the ideal solution implied by the analytical methods. Additionally, alternative screenings become redundant in order to reach an integer result and cutting plans are minimized which dramatically decrease the solution time. Instead of making preliminary specifications and accordingly 
Table 16. Comparison of the generalized approach and conventional analytical method.

\begin{tabular}{|c|c|c|c|c|}
\hline $\begin{array}{l}\text { No. of } \\
\text { part } \\
\text { types }\end{array}$ & $\begin{array}{l}\text { Possible pat- } \\
\text { terns for the } \\
\text { generalized } \\
\text { approach }\end{array}$ & $\begin{array}{l}\text { Possible pat- } \\
\text { terns for the } \\
\text { analytical } \\
\text { method }\end{array}$ & $\begin{array}{l}\text { File size }(\mathrm{KB}) \\
\text { for all possible } \\
\text { patterns for the } \\
\text { analytical } \\
\text { method }\end{array}$ & $\begin{array}{l}\text { Fraction of } \\
\text { column (2)/ } \\
\text { column (3) }\end{array}$ \\
\hline 5 & 5 & 5 & 28 & 0.179 \\
\hline 6 & 12 & 12 & 106 & 0.113 \\
\hline 7 & 40 & 40 & 600 & 0.067 \\
\hline 8 & 41 & 41 & 671 & 0.061 \\
\hline 9 & 46 & 46 & 995 & 0.046 \\
\hline 10 & 65 & 65 & 1,947 & 0.033 \\
\hline 11 & 66 & 66 & 2,129 & 0.031 \\
\hline 12 & 67 & 67 & 2,497 & 0.027 \\
\hline 13 & 68 & 68 & 2,594 & 0.026 \\
\hline 14 & 74 & 74 & 3,442 & 0.021 \\
\hline 15 & 76 & 76 & 3,928 & 0.019 \\
\hline 16 & 77 & 77 & 4,042 & 0.019 \\
\hline 17 & 101 & 101 & 7,080 & 0.014 \\
\hline 18 & 102 & 102 & 7,452 & 0.014 \\
\hline 19 & 120 & 120 & 11,046 & 0.011 \\
\hline 20 & 121 & 121 & 11,197 & 0.011 \\
\hline 21 & 122 & 122 & 12,052 & 0.010 \\
\hline 22 & 123 & 123 & 12,428 & 0.010 \\
\hline 23 & 126 & 126 & 14,513 & 0.009 \\
\hline 24 & 207 & 207 & 32,759 & 0.006 \\
\hline 25 & 208 & 208 & 34,026 & 0.006 \\
\hline 26 & 222 & 222 & 42,300 & 0.005 \\
\hline 27 & 298 & 298 & 72,992 & 0.004 \\
\hline 28 & 301 & 301 & 78,776 & 0.004 \\
\hline 29 & 302 & 302 & 79,581 & 0.004 \\
\hline 30 & 566 & 566 & 203,141 & 0.003 \\
\hline 31 & 567 & 567 & 211,215 & 0.003 \\
\hline 32 & 568 & 568 & 212,134 & 0.003 \\
\hline 33 & 569 & 569 & 214,982 & 0.003 \\
\hline 34 & 636 & 636 & 283,908 & 0.002 \\
\hline 35 & 648 & 648 & 312,401 & 0.002 \\
\hline 36 & 649 & 649 & 320,812 & 0.002 \\
\hline 37 & 702 & 702 & 395,401 & 0.002 \\
\hline 38 & 703 & 703 & 396,317 & 0.002 \\
\hline 39 & 711 & 711 & 425,090 & 0.002 \\
\hline 40 & 712 & 712 & 428,264 & 0.002 \\
\hline
\end{tabular}

ignoring many alternative arrangements, the suggested optimization technique selectively considers feasible arrangements by eliminating majority of the probable arrangements thus rendering the problem practically solvable. Another important advantage of the generalized approach is its ability to produce integer results, which usually cannot be obtained by means of analytical methods used in linear programming.
Overall, the solution of the problem is drastically simplified to allow hand calculations instead of long computer runs. In the given test cases, the overall process takes approximately 15 minutes for the first case and 12 minutes for the second case by using a hand calculator. The test cases clearly show that the cutting plan solutions are achieved with less number of patterns with the generalized approach compared to the conventional method; hence, it emerges as a time and cost efficient tool. Furthermore, the trim loss is limited to a minimum allowing efficient use of stock material. In conclusion, the generalized approach can be very functional for small shipyards and single boat builders without time consuming cumbersome computations. The generalized approach gives fast and reliable results within minutes for hand calculations, which are quite valuable in working environments with various different projects changing in relatively quick pace. For the future research, the generalized approach can be applied to 2D stock cutting and 3D part nesting applications.

\section{ACKNOWLEDGMENTS}

The authors would like to thank Hakan Once from the Tosyali Iron and Steel Ind. Company and the workers for giving their valuable time for cooperation.

\section{REFERENCES}

1. Belov, G., Letchford, A., and Uchoa, E. A, "Node-flow model for onedimensional stock cutting: Robust branch \& cut \& price," Niteroi: Technical Report RPEP, Vol. 5, No. 7, Universidade Federal Fluminense, Engenharia de Producao (2005).

2. Belov, G. and Scheithauer, G., "A branch-and-cut-and-price algorithm for one-dimensional stock cutting and two-dimensional two-stage cutting," European Journal of Operational Research, Vol. 171, No. 1, pp. 85-106 (2006).

3. Belov, G. and Scheithauer, G., "A cutting plane algorithm for the one-dimensional cutting stock problem with multiple stock lengths," European Journal of Operational Research, Vol. 141, No. 2, pp. 274-294 (2002).

4. Bingul, Z. and Oysu, C., "Comparison of stochastic and approximation algorithms for one-dimensional cutting problems," In: Huang, D. S., Zhang, X. P., and Huang, G. B. (Eds.), Advances in Intelligent Computing, International Conference on Intelligent Computing Part I, pp. 976-985 (2005).

5. De Carvalho, J. M. V., "Exact solution of bin-packing problems using column generation and branch-and-bound," Annals of Operations Research, Vol. 86, pp. 629-659 (1999).

6. Dikili, A. C., "A new approach for the solution of the two-dimensional guillotine-cutting problem in ship production," Ocean Engineering, Vol. 31, No. 8-9, pp. 1193-1203 (2004).

7. Dikili, A. C., Computer Aided Optimized Material Use in Ship Production, Ph.D. Thesis, Istanbul Technical University, Istanbul (1991). (in Turkish)

8. Dikili, A. C., Sarioz, E., and Pek, N. A., "A successive elimination method for one-dimensional stock cutting problems in ship production," Ocean Engineering, Vol. 34, No. 13, pp. 1841-1849 (2007).

9. Dikili, A. C., Takinaci, A. C., and Pek, N. A., "A new heuristic approach to one-dimensional stock-cutting problems with multiple stock lengths in ship production," Ocean Engineering, Vol. 35, No. 7, pp. 637-645 (2008).

10. Dyckhoff, H., "A new linear programming approach to the cutting-stock problem," Operations Research, Vol. 29, pp. 1092-1104 (1981).

11. Dyckhoff, H., "A typology of cutting and packing problems," European Journal of Operational Research, Vol. 44, pp. 45-159 (1990). 
12. Gilmore, P. C. and Gomory, R. E., "A linear programming approach to the cutting-stock problem,” Operations Research, Vol. 9, pp. 849-859 (1961).

13. Gilmore, P. C. and Gomory, R. E., "A linear programming approach to the cutting-stock problem Part II,” Operations Research, Vol. 11, pp. 863-888 (1963).

14. Gilmore, P. C. and Gomory, R. E., "Multi-stage cutting-stock problems of two or more dimensions," Operations Research, Vol. 13, pp. 94-120 (1965).

15. Hifi, M. and Ouafi, R., "Best-first search and dynamic programming methods for cutting problems: the cases of one or more stock plates," Computers and Engineering, Vol. 32, No. 1, pp. 187-205 (1997).

16. Hinterding, R. and Khan, L., "Genetic algorithms for cutting stock problems: with and without contiguity," In: Yao, X. (Ed.), Lecture Note in Artifcial Intelligence, Springer, New York, pp. 166-186 (1995).

17. Johnston, R. E. and Sadinlija, E., “A new model for complete solutions to one-dimensional stock problems," European Journal of Operational Research, Vol. 153, pp. 176-183 (2004).

18. Scheithauer, G., Terno, J., Muller, A., and Belov, G., "Solving one dimensional cutting stock problems exactly with a cutting plane algorithm," Journal of the Operational Research Society, Vol. 52, pp. 1390-1401 (2001).

19. Stadtler, H., "One-dimensional cutting stock problem in the aluminum industry and its solution," European Journal of Operational Research, Vol. 44, pp. 209-224 (1990).
20. Umetani, S., Yagiura, M., and Ibaraki, T., "One-dimensional cutting stock problem to minimize the number of different patterns," European Journal of Operational Research, Vol. 146, No. 2, pp. 388-402 (2003).

21. Vance, P., "Branch-and-price algorithms for the one-dimensional cutting stock problem," Computational Optimization and Applications, Vol. 9, No. 3, pp. 211-228 (1998).

22. Vance, P., Barnhart, C., Johnson, E. L., and Nemhauser, G. L., "Solving binary cutting stock problems by column generation and branch-andbound," Computational Optimization and Applications, Vol. 3, No. 2, pp. 111-130 (1994).

23. Vanderbeck, F., "Computational study of a column generation algorithm for bin-packing and cutting stock problems," Mathematical Program$\operatorname{ming} A$, Vol. 86, pp. 565-594 (1999).

24. Vanderbeck, F., "On Dantzig-Wolfe decomposition in integer programming and ways to perform branching in a branch-and-price algorithm," Operations Research, Vol. 48, pp. 111-128 (2000).

25. Waescher, G. and Gau, T., "Heuristics for the integer one-dimensional cutting stock problem: A computational study," OR Spektrum, Vol. 18, No. 3, pp. 131-144 (1996).

26. Wagner, B. J., "A genetic algorithm solution for one-dimensional bundled stock cutting," European Journal of Operational Research, Vol. 117, No. 2, pp. 368-381 (1999). 